\title{
Long-Chain Polyorthoesters as Degradable Polyethylene Mimics
}

\author{
Tobias Haider, ${ }^{\dagger}$ Oleksandr Shyshov, ${ }^{\dagger}$ Oksana Suraeva, ${ }^{\dagger}$ Ingo Lieberwirth, ${ }^{\dagger}$ (i) Max von Delius, ${ }^{\ddagger 0}$ \\ and Frederik R. Wurm* ${ }^{*}+$ (1) \\ ${ }^{\dagger}$ Max Planck Institute for Polymer Research, Ackermannweg 10, 55128 Mainz, Germany \\ ${ }^{\ddagger}$ Institute of Organic Chemistry and Advanced Materials, University of Ulm, Albert-Einstein-Allee 11, 89081 Ulm, Germany
}

Supporting Information

\begin{abstract}
The persistence of commodity polymers makes the research for degradable alternatives with similar properties necessary. Degradable polyethylene mimics containing orthoester groups were synthesized by olefin metathesis polymerization for the first time. Ring-opening metathesis copolymerization (ROMP) of 1,5-cyclooctadiene with four different cyclic orthoester monomers gave linear copolymers with molecular weights up to $38000 \mathrm{~g} \mathrm{~mol}^{-1}$. Hydrogenation of such copolymers produced semicrystalline polyethylenelike materials, which were only soluble in hot organic solvents. The crystallinity and melting points of the materials were controlled by the orthoester content of the copolymers. The polymers crystallized similar to polyethylene, but the relatively bulky orthoester groups were expelled from the crystal lattice. The lamellar thickness of the crystals was dependent on the amount of the orthoester groups. In addition, the orthoester substituents influenced the hydrolysis rate of the polymers in solution. Additionally, we were able to prove that non-hydrogenated copolymers with a high orthoester content were biodegraded by microorganisms from activated sludge from a local sewage plant. In general, all copolymers hydrolyzed under ambient conditions over a period of several months. This study represents the first report of hydrolysis-labile and potentially biodegradable PE mimics based on orthoester linkages. These materials may find use in applications that require the relatively rapid release of cargo, e.g., in biomedicine or nanomaterials.
\end{abstract}

\section{INTRODUCTION}

Today polyethylene (PE) is the most used commodity polymer in the world. ${ }^{1}$ Because of its excellent mechanical properties, PE is used for a variety of applications. ${ }^{2}$ However, there are environmental issues related to the low degradability of $\mathrm{PE}$ in the environment. Increasing plastic pollution in natural environments amplifies the need for degradable alternatives. $^{3}$

To mimic the properties of polyethylene while potentially enabling degradation at the same time, one approach lies in the incorporation of functional groups in long aliphatic polymer chains. ${ }^{4}$ Among others, long-chain polyesters, ${ }^{5}$ polyamides, ${ }^{6}$ polyketones, $^{7}$ or polyphosphoesters ${ }^{8}$ have been reported. There, the functional groups act as "defects" in the polymer chains of the semicrystalline materials. Depending on their size, the defects are either part of the lamellar PE crystals (small defect size) or forced into the amorphous phase (bulky defects). ${ }^{9}$ An increasing number of methylene units between the functional groups enhances van der Waals interactions between the polymer chains, leading to a higher degree of crystallinity. ${ }^{4}$ As a result, hydrophobicity, melting temperature, and stiffness of the material increase. ${ }^{4}$ Yet, concerning degradability, long-chain polyesters, for example, did not show relevant enzymatic or hydrolytic degradation as water is hindered from penetrating into the materials due to the high crystallinity and hydrophobicity. ${ }^{4}$ Also, long chain polyacetals revealed only minor degradation in acidic media. ${ }^{10}$ Thus, the use of functional groups, which are more prone to hydrolysis, is advisable. Similar to acetals in molecular structure, but with a higher hydrolysis rate ${ }^{11}$ and steric bulk, orthoesters can be a suitable alternative to synthesize acid-sensitive polymers.

Acid-degradable polymers are also attractive for drug delivery; ${ }^{12}$ polyorthoesters were developed in the 1970 s by the group of Jorge Heller for biomedical applications. ${ }^{13-16}$ The hydrolysis of polyorthoesters in acidic media yields alcohols and esters (Scheme 1), while the degradation of the bulk material was shown to proceed via surface erosion. ${ }^{15}$

While polyacetals were synthesized by acyclic diene metathesis (ADMET) polymerization, ${ }^{17,18}$ ring-opening metathesis copolymerization (ROMP), ${ }^{19}$ or polycondensation, ${ }^{20}$ polyorthoesters are mainly prepared either through transesterification of orthoesters with diols or through polyaddition between a diol and a diketene acetal (Scheme 2). ${ }^{21}$

Received: January 24, 2019

Revised: February 27, 2019

Published: March 13, 2019 
Scheme 1. Hydrolysis of Polyorthoesters to Alcohols and Esters

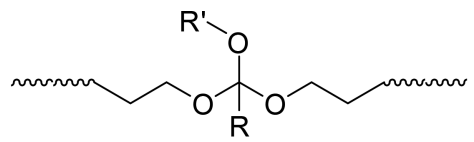<smiles>[R]OCCCCCCCCO</smiles><smiles>[R]OC([R])=O</smiles>

Scheme 2. Synthesis Methods for Polyorthoesters

\section{J. Heller:}

Transesterfication

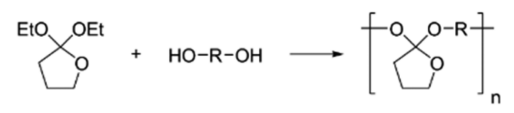

Polyaddition

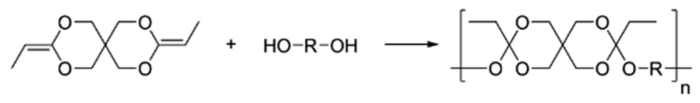

This work:

ROMP

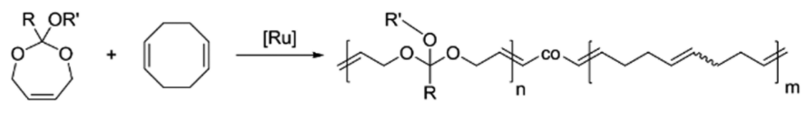

Dove et al. reported the synthesis of different polyorthoesters by polyaddition using bifunctional, air- and moisture-stable vinyl acetal precursors. ${ }^{22}$ In general, the mechanical and thermal properties of polyorthoesters can be adjusted by varying the structure of the monomers (mainly the diols). By changing the hydrophobicity of the polymer, the degradability of the material can be tuned. However, this requires the use of new, different monomers if the polymerization is conducted by transesterification or polyaddition. Recently, von Delius and co-workers explored the use of orthoesters for the selfassembly of novel supramolecular hosts ${ }^{23-25}$ and in this context demonstrated that the degradation rate of orthoesters strongly depends on the orthoester substituent ( $\mathrm{R}$ group in Scheme 1): electron-rich orthoesters $\left(\mathrm{R}=-\mathrm{CH}_{3}\right)$ hydrolyze even at neutral $\mathrm{pH}$, while more electron-deficient orthoesters $\left(\mathrm{R}=-\mathrm{CCl}_{3}\right)$ are remarkably stable. ${ }^{26}$ For drug delivery applications, von Delius recommend the use of orthoformates $(\mathrm{R}=-\mathrm{H})$ and chloromethyl-substituted orthoesters $(\mathrm{R}=$ $-\mathrm{CH}_{2} \mathrm{Cl}$ ) based on observed hydrolysis half-lives of 20 and $120 \mathrm{~min}$ at $\mathrm{pH} \mathrm{5}$, respectively.

In this work, we present a straightforward approach to longchain polyorthoesters by performing for the first time a ringopening metathesis copolymerization of cyclic orthoesters with 1,5-cyclooctadiene followed by exhaustive hydrogenation. By the variation of the comonomer ratio, the number of methylene groups between two orthoester units can be controlled. Monomers featuring three different orthoester substituents were studied based on the hypothesis that the corresponding polymers would differ in hydrolysis rate. The thermal and mechanical properties of the polyethylene-like polymers were studied as well as the degradation in an organic solvent and in aqueous media.

\section{RESULTS AND DISCUSSION}

Monomer Synthesis. Starting from the corresponding orthoesters trimethyl orthoacetate, trimethyl orthoformate, triisopropyl orthoformate, and 2-chloro-1,1,1-trimethoxyethane, we synthesized four different cyclic orthoester monomers $(\mathbf{1}-4)$ by reacting the respective starting compounds with cis-2-butene-1,4-diol under acidic catalysis (Scheme 3A). Moisture had to be strictly excluded during these procedures, as it would lead to hydrolysis of the orthoester. The monomers were purified by (repeated) distillation to yield colorless oils.

Ring-Opening Metathesis Polymerization. The cyclic orthoester monomers are seven-membered and substituted 4,7-dihydro-1,3-dioxepins (Scheme 3) with a substitution at the C2. In previous works, Kilbinger and co-workers synthesized polyacetals as sacrificial blocks to prepare telechelic polynorbornenes using dioxepins. ${ }^{27}$ Grubbs et al. reported the ROMP of 4,7-dihydro-1,3-dioxepine and phenyl-substituted 4,7-dihydro-2-phenyl-1,3-dioxepin to polyacetals. ${ }^{19}$ However, they were able to prove that only the unsubstituted dioxepin underwent successful homopolymerization. In contrast, we were able in previous work to produce homopolymers of phosphorus-containing seven-membered rings, namely 2-phenoxy-4,7-dihydro-1,3,2-dioxaphosphepine 2-oxide ${ }^{28}$ and 2-methyl-4,7-dihydro-1,3,2-dioxaphosphepine 2oxide. $^{8}$

To date, no polyorthoesters have been reported by metathesis polymerization. In accordance with previous studies, the attempted homopolymerization of the orthoester monomers $\mathbf{1}$ and $\mathbf{2}$ did not yield any polymers, even if catalyst type and conditions were varied (cf. Table S1).

During ROMP, the release of ring strain of the cyclic olefin is the driving force of the polymerization. ${ }^{29}$ The unsubstituted dioxepin, however, already exhibits relatively low ring strain. Further substituents hinder the ROMP due to the ThorpeIngold effect: substituents on a ring stabilize the ring-closed form relative to the linear counterpart. With ROMP being an equilibrium process, the Thorpe-Ingold effect results in a higher critical monomer concentration. This leads to a lower yield of the linear polymer-or to no polymer at all. ${ }^{30-32}$ However, monomers with low ring strain can be activated by a more active comonomer: the copolymerization of 1,5-cyclooctadiene (COD) with an unsubstituted or a methylsubstituted 4,7-dihydro-1,3-dioxepins gave statistical COD/ dioxepin copolymers. ${ }^{19}$ Thus, we followed this approach to copolymerize our four cyclic orthoester monomers with COD using a first-generation Hoveyda-Grubbs catalyst as the initiator $(0.4 \mathrm{~mol} \%$ relative to the total amount of comonomers). The polymerizations were conducted in bulk at room temperature overnight, yielding polymers with apparent molecular weights up to $38000 \mathrm{~g} \mathrm{~mol}^{-1}$ (by SEC vs polystyrene standard). Monomers $\mathbf{1 - 4}$ were transformed successfully into copolymers with different amounts of orthoesters incorporated into the polymer chain, which controls the chain length of the degradation products (Table $1)$.

In comparison to the monomers, the corresponding ${ }^{1} \mathrm{H}$ NMR spectra show a shift of both the orthoester double bond 
Scheme 3. (A) Synthesis of Cyclic Orthoester Monomers for ROMP (1-4), (B) ROMP Homopolymerization and (C) Copolymerization of Cyclic Orthoesters with 1,5-Cyclooctadiene and Subsequent Hydrogenation to Orthoester-Containing PE Mimics

A Monomer synthesis<smiles>[R]OC([R])([R])[O+]</smiles>

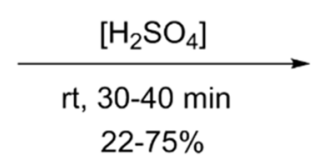

B Homo polymerization<smiles>[R]C1([R])OCC=CCO1</smiles><smiles>CC(C)(C)C(C)(C)C</smiles><smiles>[R]OC([R])(OCC=C)OCC=C</smiles>

\section{Copolymerization and hydrogenation}
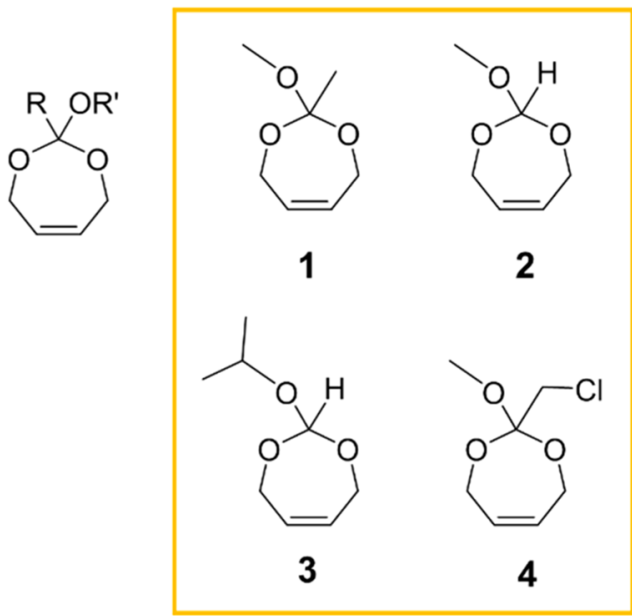

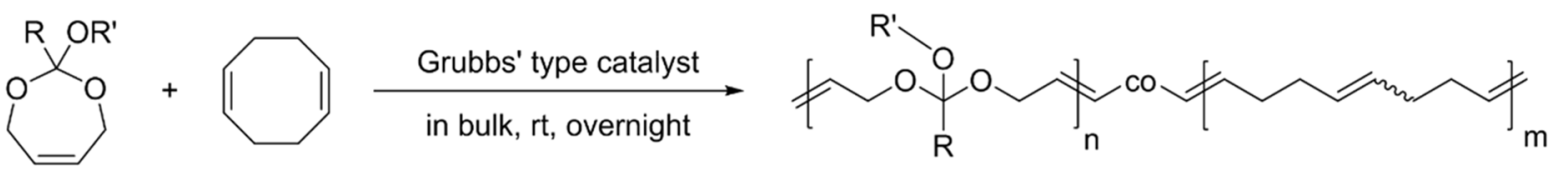<smiles>[R]OC([R])(OCCC(C)(C)COC(C)(C)CCCCCCCCC(C)(C)C)OCCC(C)(C)OC(=O)OCC</smiles>

Table 1. Copolymerization of Orthoester Monomers 1-4 with Cyclooctadiene Using First-Generation Grubbs-Hoveyda Catalyst $^{a}$

\begin{tabular}{|c|c|c|c|c|c|c|}
\hline monomer & ortho:COD feed & ortho:COD NMR ${ }^{d}$ & $M_{\mathrm{n}}^{e}\left[\mathrm{~g} \mathrm{~mol}^{-1}\right]$ & $M_{\mathrm{w}}^{e}\left[\mathrm{~g} \mathrm{~mol}^{-1}\right]$ & $M_{\mathrm{n}} / M_{\mathrm{w}}{ }^{e}$ & yield $[\%]$ \\
\hline $\mathbf{1}^{b}$ & $1: 1$ & $1: 2$ & 900 & 1200 & 1.43 & n.d. \\
\hline $\mathbf{1}^{b}$ & $1: 2$ & $1: 3.5$ & 1300 & 2000 & 1.61 & n.d. \\
\hline $1^{b}$ & $1: 4$ & $1: 6.5$ & 1700 & 3100 & 1.79 & n.d. \\
\hline 2 & $1: 1$ & $1: 2$ & 10500 & 22500 & 2.14 & 60 \\
\hline 2 & $1: 2$ & $1: 4$ & 11000 & 32200 & 2.95 & 83 \\
\hline 2 & $1: 4$ & $1: 6$ & 15000 & 31000 & 2.60 & n.d. \\
\hline $\mathbf{2}^{c}$ & $1: 4$ & $1: 9$ & 11600 & 30800 & 2.66 & n.d. \\
\hline 3 & $1: 1$ & $1: 2$ & 5600 & 15000 & 2.75 & 47 \\
\hline 3 & $1: 2$ & $1: 3$ & 8400 & 16600 & 1.99 & 65 \\
\hline 3 & $1: 4$ & $1: 5$ & 11000 & 24000 & 2.20 & 77 \\
\hline $3^{c}$ & $1: 4$ & $1: 9$ & 10700 & 27300 & 2.54 & 75 \\
\hline 4 & $1: 1$ & $1: 2.5$ & 6300 & 15300 & 2.42 & n.d. \\
\hline 4 & $1: 2$ & $1: 3.5$ & 8900 & 24700 & 2.79 & 75 \\
\hline 4 & $1: 4$ & $1: 7$ & 12700 & 38100 & 3.01 & 82 \\
\hline
\end{tabular}

${ }^{a}$ All polymerizations were performed overnight at room temperature with first-generation Grubbs-Hoveyda catalyst $(0.4 \mathrm{~mol} \%)$ in bulk. ${ }^{b} 48 \mathrm{~h}$ polymerization time. ${ }^{c}$ Large-scale polymerization $(>10 \mathrm{~g}) .{ }^{d}$ Determined by ${ }^{1} \mathrm{H}$ NMR. ${ }^{e}$ Determined by SEC.

and the $-\mathrm{O}-\mathrm{CH}_{2}$ group of the orthoester monomers to lower field (Figure 1). Overlapping poly-COD signals with slightly different chemical shifts elucidate the copolymer sequence as for poly(1)-co-COD, where the signal at $2.12 \mathrm{ppm}$ corresponds to the $-\mathrm{CH}_{2}$ group of a COD unit next to another COD unit, while the signal at $2.06 \mathrm{ppm}$ indicates a neighboring orthoester unit. Additional information about the copolymer sequence is given by the signals corresponding to the polyorthoester double bonds: the signal at $5.72 \mathrm{ppm}$ corresponds to an orthoester-COD dyad. The small signal at $5.90 \mathrm{ppm}$, however, is giving a hint on an orthoester-orthoester dyad, even though the homopolymerization of $\mathbf{1}$ previously was not achieved.

By integration of the resonances of COD at $2.09 \mathrm{ppm}$ and comparison to the orthoester resonances at $3.23 \mathrm{ppm}$, the relative ratio of orthoester to $\mathrm{COD}$ in the polymer was determined (indicated in the text by indices as in poly $(\mathbf{1})_{1}$-co$\mathrm{COD}_{2}$ ). The experimentally determined ratio is lower than the feed ratio since $\mathrm{COD}$ is the more reactive monomer during ROMP. The incorporation of orthoester units into the polymer chain was dependent on several factors: First, a lower amount 


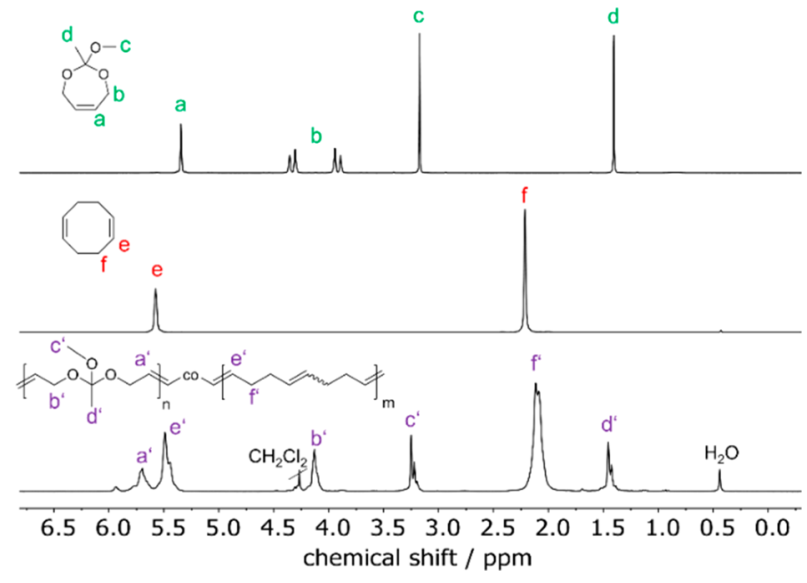

Figure 1. ${ }^{1} \mathrm{H}$ NMR ( $300 \mathrm{MHz}$ at $298 \mathrm{~K}$, in $\mathrm{C}_{6} \mathrm{D}_{6}$ ) of monomer 1 (top), cyclooctadiene (COD, middle), and the corresponding copolymer $\operatorname{poly}(\mathbf{1})_{1}$-co- $\mathrm{COD}_{2}$ (bottom).

of initiator to monomers resulted in lower incorporation of the orthoester monomer (Table S1). Performing the polymerization in diluted conditions using THF as a solvent decreased the orthoester content in the copolymer in comparison to the polymerization in bulk. In terms of the initiator, the firstgeneration Grubbs-Hoveyda catalyst revealed the highest conversion of the orthoester monomers. The more active second-generation Grubbs-Hoveyda catalyst and third-generation Grubbs catalyst led to rapid consumption of COD, and no incorporation of 1-4 was detected. Increasing the amount of 1-4 in the monomer feed resulted in increased incorporations, however, always lower than the monomer feed ratio (20-65\% lower than feed). When the copolymerizations of $\mathbf{2}$ and $\mathbf{3}$ with COD were performed at a larger scale (ca. $10 \mathrm{~g}$ ), lower incorporations were obtained compared to the small scale reactions $(200-400 \mathrm{mg}$ ).

Polymerizations were terminated by the addition of ethyl vinyl ether and isolated by precipitation into basic methanol (ca. $1 \mathrm{wt} \%$ of triethylamine were added to prevent hydrolysis). The polymers were recovered as brown viscous oils, indicating that the initiator could not be removed completely by simple precipitation. As the ROMP of COD produces linear poly $(1,4-$ butadiene) with a mixture of cis- and trans-configurated double bonds, crystallization of the polymer chains is hindered, ${ }^{33}$ and all copolymers exhibited melting temperatures below room temperature $\left(T_{\mathrm{m}}\right.$ maximum $\left.-9{ }^{\circ} \mathrm{C}\right)$.

To produce $\mathrm{PE}$-like materials, we performed hydrogenation of the polymers with $\mathrm{Pd}$ on $\mathrm{CaCO}_{3}$ in toluene at temperatures above $70{ }^{\circ} \mathrm{C}$. Because of the high sensitivity of orthoesters toward hydrolysis in solution, the hydrogenation proved to be challenging. Despite using of anhydrous conditions and the addition of DIPEA (a soluble and relatively high-boiling amine base) certain hydrolysis of the orthoester functionality could not be prevented. Presumably, the remaining Grubbs' type catalyst could have caused the hydrolysis since $\mathrm{HCl}$ can be abstracted during the decomposition of the catalyst. ${ }^{34}$ Especially the most sensitive poly $(\mathbf{1})$-co-COD $(\mathrm{R}=$ methyl) hydrolyzed rapidly. Furthermore, the solubility of the copolymers reduced drastically with ongoing hydrogenation, resulting in the copolymers being insoluble in toluene at room temperature. Thus, for purification the copolymers were dissolved in boiling toluene, the catalyst was filtered off while the solution was still hot, and the copolymers were immediately precipitated into methanol containing DIPEA. The obtained off-white, solid materials were hard and partly brittle. The ${ }^{1} \mathrm{H}$ NMR spectrum of poly(3)-co-COD in toluene$d_{8}$ (at $90{ }^{\circ} \mathrm{C}$ ) proves the successful hydrogenation, as the resonances of the double bonds had disappeared completely, while an intense alkyl signal at $1.4 \mathrm{ppm}$ indicates the presence of only methylene groups in the saturated polymer (Figure 2).

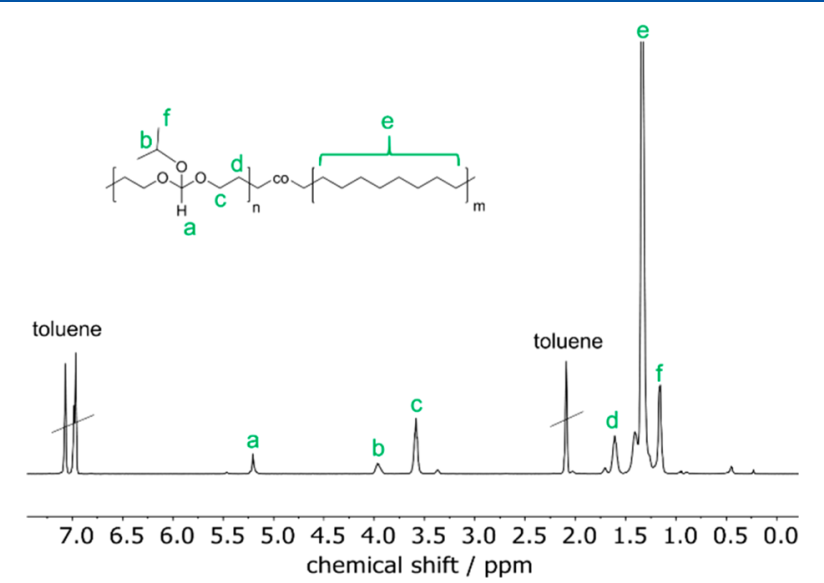

Figure 2. ${ }^{1} \mathrm{H}$ NMR $\left(500 \mathrm{MHz}\right.$ at $353 \mathrm{~K}$, in toluene- $\left.d_{8}\right)$ of hydrogenated copolymer poly $(3)_{1}-c o-\mathrm{COD}_{2}$.

Solid-State Characterization. The non-hydrogenated poly(orthoester)-co-COD copolymers are honey-like, viscous oils, while the hydrogenated polymers are hard, solid materials. Yet, the hydrogenated copolymers were brittle, so we were unable to make a specimen for tensile strength tests. Possibly the molecular weights of the synthesized polymers were too low, as Gross and co-workers reported a brittle-to-ductile transformation for long-chain polyesters for an $M_{\mathrm{w}}$ between 53 $\times 10^{3}$ and $78 \times 10^{3} \mathrm{~g} \mathrm{~mol}^{-1}$. ${ }^{35}$ The thermal stabilities of the copolymers were examined with thermal gravimetric analysis (TGA). The first derivative shows two main points of degradation (Figure S36), indicating that the orthoester and COD units degrade at different temperatures. For instance, hydrogenated poly $(3)_{1}$-co- $\mathrm{COD}_{3}$ has one main point of degradation at $343{ }^{\circ} \mathrm{C}$ and one at $475{ }^{\circ} \mathrm{C}$ (compared to 483 ${ }^{\circ} \mathrm{C}$ of HDPE). Furthermore, the weight loss after the first degradation process is dependent on the orthoester content in the copolymer (Figure 3A). For instance, the thermogram of hydrogenated poly $(3)_{1}$-co-COD 2 reveals a weight loss of about $40 \%$ after the first degradation process, which matches the mol $\%$ of the orthoester monomers in the polymer. In general, the hydrogenated polymers are remarkably stable at elevated temperatures with an onset temperature $\left(T_{\text {on }}\right)$ after $5 \%$ degradation for e.g. $\operatorname{poly}(3)_{1}-\mathrm{co}-\mathrm{COD}_{5}$ at $338{ }^{\circ} \mathrm{C}$, which is about $100{ }^{\circ} \mathrm{C}$ below the measured $T_{\text {on }}$ of HDPE. The nonhydrogenated copolymers decompose at lower temperatures in comparison to the related hydrogenated polymers (Figure 3 B). As an example, $T_{\text {on }}$ after $5 \%$ degradation for nonhydrogenated poly $(3)_{1}-c o-\mathrm{COD}_{5}$ is $265{ }^{\circ} \mathrm{C}$.

By differential scanning calorimetry (DSC), the melting points $\left(T_{\mathrm{m}}\right)$ and the crystallinity were determined. In most cases, a glass transition point was either not detectable or outside the measured range (minimum $-100{ }^{\circ} \mathrm{C}$ ). While the non-hydrogenated polymers are either amorphous or show a $T_{\mathrm{m}}$ below room temperature, the hydrogenated polymers have $T_{\mathrm{m}}$ up to $117{ }^{\circ} \mathrm{C}$ for $\operatorname{poly}(2)_{1}-c_{0}-\mathrm{COD}_{9}$, which is similar to 
A

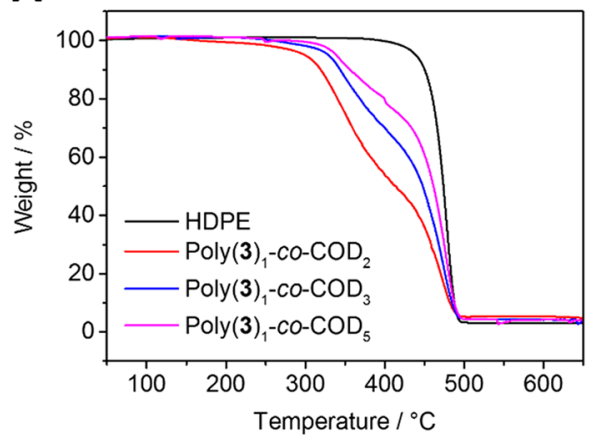

C

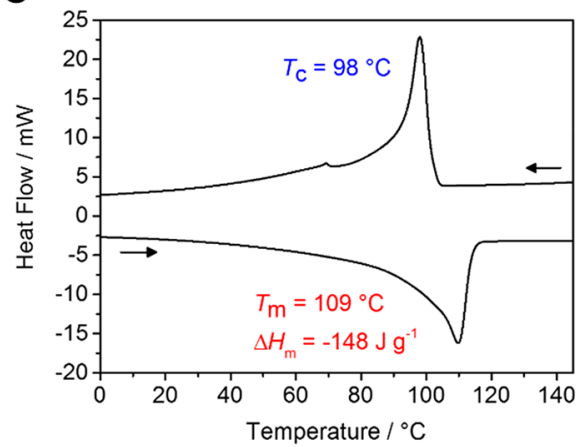

B

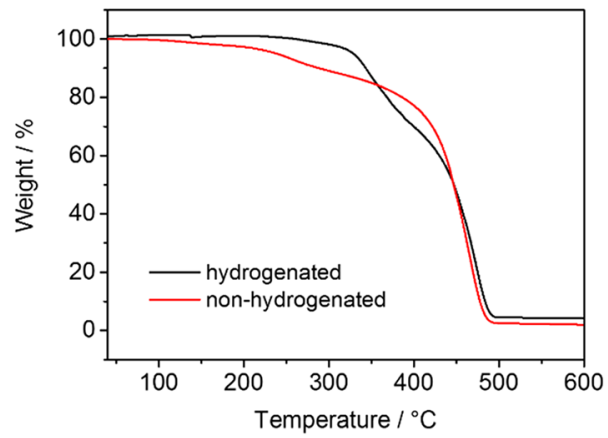

D

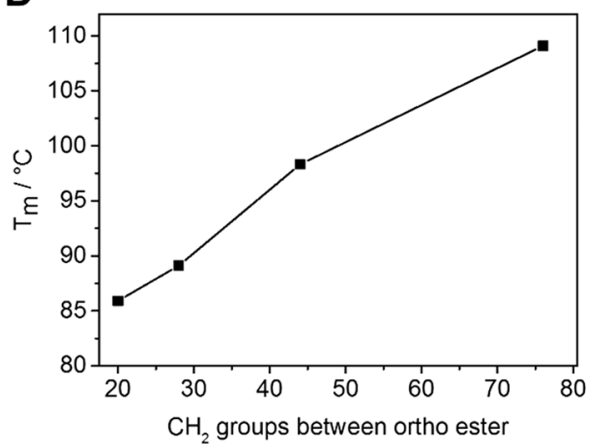

Figure 3. (A) TGA thermogram of hydrogenated poly $(3)_{1}-c o-\mathrm{COD}_{2}$, poly $(3)_{1}-c o-\mathrm{COD}_{3}$, poly $(3)_{1}-c o-\mathrm{COD}_{5}$, and HDPE. (B) TGA thermogram of hydrogenated (black) and non-hydrogenated (red) poly $(3)_{1}-c o-C_{3}$. (C) DSC thermogram of poly $(3)_{1}-c o-C_{1} D_{9}$ (exo up, heating and cooling rate $10 \mathrm{~K} \mathrm{~min}^{-1}$ (second run)). (D) Correlation of melting point $T_{\mathrm{m}}$ (from DSC) and the number of $\mathrm{CH}_{2}$ groups between orthoester (by ${ }^{1} \mathrm{H}$ NMR) for poly(3)-co-COD.

completely linear PE with $134{ }^{\circ} \mathrm{C}^{6}$ (cf. Figure $3 \mathrm{C}$ shows the DSC thermogram of poly $(3)_{1}-\mathrm{co}-\mathrm{COD}_{9}$ with $\left.T_{\mathrm{m}}=109{ }^{\circ} \mathrm{C}\right)$. The melting enthalpies $\Delta H_{\mathrm{m}}$ were between -84 and $-162 \mathrm{~J}$ $\mathrm{g}^{-1}$ and was compared to $\Delta H$ of $100 \%$ crystalline polyethylene $\left(\Delta H_{\mathrm{m}}=293 \mathrm{~J} \mathrm{~g}^{-1}\right)^{36}$ to calculate the crystallinity of the hydrogenated polymers. Both crystallinity and melting temperatures increased with increasing number of methylene groups between the orthoester groups, as the material becomes more similar to PE (cf. Table 2 and Figure 3D). The melting temperatures of our PE mimics start at ca. $86^{\circ} \mathrm{C}$ for poly $(3)_{1}$ co- $\mathrm{COD}_{2}$, which on average has $20 \mathrm{CH}_{2}$ groups between the orthoester groups (determined by ${ }^{1} \mathrm{H}$ NMR), and increase to $109{ }^{\circ} \mathrm{C}$ for poly $(3)_{1}-c o-\mathrm{COD}_{9}$ with on average $76 \mathrm{CH}_{2}$ groups as spacer (Figure 3D). Thus, with increasing COD amount in

Table 2. Thermal Properties of Hydrogenated Copolymers

\begin{tabular}{|ccccc} 
polymer & ortho:COD ${ }^{a}$ & $\begin{array}{c}T^{b}{ }^{b} \\
{\left[{ }^{\circ} \mathrm{C}\right]}\end{array}$ & $\begin{array}{c}\Delta H^{b} \\
{\left[\mathrm{~J} \mathrm{~g}^{-1}\right]}\end{array}$ & $\begin{array}{c}\text { crystallinity }^{c} \\
{[\%]}\end{array}$ \\
\hline poly(1)-co-COD & $1: 2$ & 102 & -156 & 53 \\
poly(1)-co-COD & $1: 3.5$ & 109 & -167 & 57 \\
poly(2)-co-COD & $1: 4.5$ & 92 & -116 & 39 \\
poly(2)-co-COD & $1: 9$ & 117 & -163 & 55 \\
poly(3)-co-COD & $1: 2$ & 86 & -84 & 29 \\
poly(3)-co-COD & $1: 3$ & 89 & -93 & 32 \\
poly(3)-co-COD & $1: 5$ & 98 & -95 & 33 \\
poly(3)-co-COD & $1: 9$ & 109 & -148 & 51 \\
poly(4)-co-COD & $1: 3.5$ & 93 & -86 & 29 \\
poly(4)-co-COD & $1: 7$ & 104 & -116 & 40
\end{tabular}

${ }^{a}$ Determined by ${ }^{1} \mathrm{H}$ NMR. ${ }^{b}$ Determined by DSC. ${ }^{c}$ Relative to $100 \%$ crystalline PE $\left(\Delta H_{\mathrm{m}}=-293 \mathrm{~J} \mathrm{~g}^{-1}\right)$. the copolymer, the melting point of the hydrogenated polymers converges toward the value for PE.

The crystal structures of the three hydrogenated copolymers poly $(2)_{1}-c o-\mathrm{COD}_{9}$, poly $(3)_{1}-c o-\mathrm{COD}_{9}$, and poly $(4)_{1}-c o-\mathrm{COD}_{9}$ were compared to HDPE by XRD (Figure 4). A similar peak

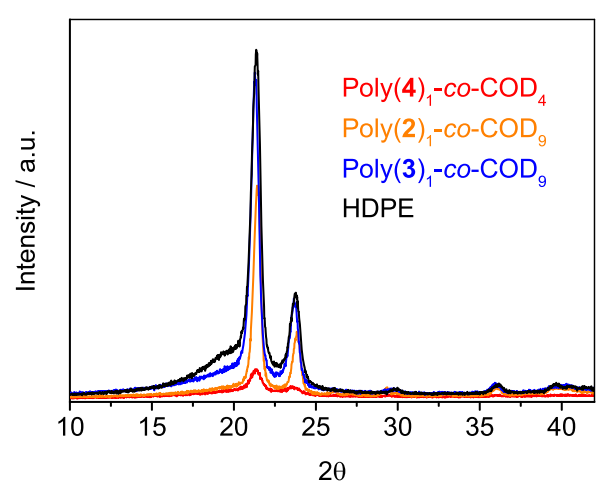

Figure 4. XRD diffractograms of hydrogenated poly $(2)_{1}-c o-\mathrm{COD}_{9}$, poly $(3)_{1}-c o-\mathrm{COD}_{4}$, and poly $(4)_{1}-c o-\mathrm{COD}_{9}$ and HDPE.

pattern in the X-ray diffractogram indicates an orthorhombic structure like HDPE in all three copolymer samples. The intensity of the peaks correlates with the degree of crystallinity.

The crystallization behavior of the orthoester-PE mimics was studied by drop-cast TEM measurements of solution grown crystals. Figure 5 shows a TEM micrograph of solutiongrown crystals of hydrogenated poly $(2)_{1}-c_{-}-C_{0 D}$, prepared from cooling a $0.05 \%$ solution of the polymer in $n$-octane to room temperature. The solution was heated to $70{ }^{\circ} \mathrm{C}$ in a temperature-controlled oil bath for $1 \mathrm{~h}$ and slowly cooled to 


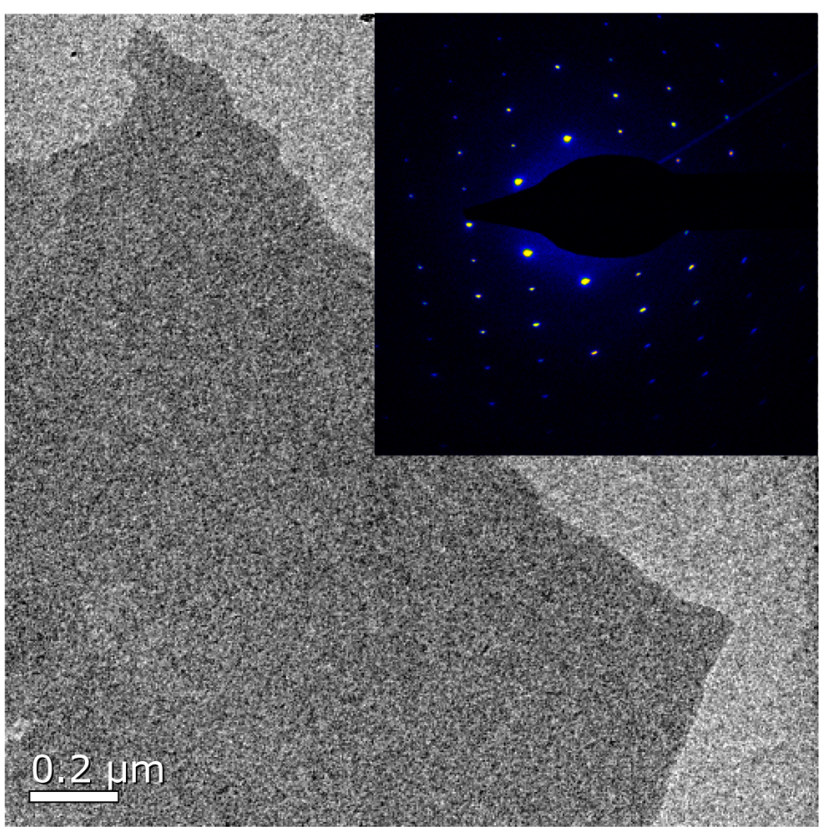

Figure 5. TEM bright-field micrograph and corresponding diffraction pattern (inset) of hydrogenated poly $(2)_{1}-$ co-COD 9 .

room temperature. One drop of this dispersion was applied to a carbon-coated TEM grid, excess liquid was blotted off with a filter paper, and the specimen was allowed to dry under ambient conditions. This preparation led to the formation of anisotropic polymer platelets with a thickness of only a few nanometers and much higher lateral dimensions (Figure 5). Electron diffraction correlated to XRD data and reveals the single crystal pattern of flat-on orthorhombic PE crystals. All these polymers have similar crystal structure as common PE, and the introduction of orthoester defects into the PE main chain does not alter the crystal structure.

Moreover, the influence of defect frequency on lamellar thickness was studied using energy-filtered transmission electron microscopy (EFTEM) thickness mapping. Measurement of the crystals of hydrogenated poly $(3)_{1}-c o-\mathrm{COD}_{2}$ and poly $(3)_{1}-c o-\mathrm{COD}_{5}$ with an average number of $\mathrm{CH}_{2}$ groups between ortho esters of 20 and 44, respectively, was carried out. This experiment revealed that the mean total lamellar thickness is $\sim 3.7 \mathrm{~nm}$ for poly $(3)_{1}-c o-\mathrm{COD}_{2}$ and $9.8 \mathrm{~nm}$ for poly $(3)_{1}-\mathrm{co}-\mathrm{COD}_{5}$, demonstrating that randomly distributed orthoester groups along the polymer chain control the averaged thickness of PE-platelets; i.e., a decreased amount of orthoester groups resulted in an increased thickness of the polymer platelets. Furthermore, the mean total lamellar thickness for poly $(3)_{1}-\mathrm{co}-\mathrm{COD}_{2}$ was higher compared to the value for polyethylene with precise butyl branches at every 21 st carbon $(2.9 \mathrm{~nm})$. $^{9}$

Polymer Degradation. The degradation of polyorthoesters in acidic media occurs by hydrolysis to the corresponding alcohols and esters (Scheme 1). We varied the $\mathrm{R}^{\prime}$ group to change the molecular structure of the degradation products. While the hydrolysis of poly(1)-co-COD, poly(2)-co-COD, and poly(4)-co-COD yields methanol, poly(3)-co-COD produces less toxic isopropanol. Furthermore, the substituent at the orthoester group has an influence on the hydrolysis rate:
A

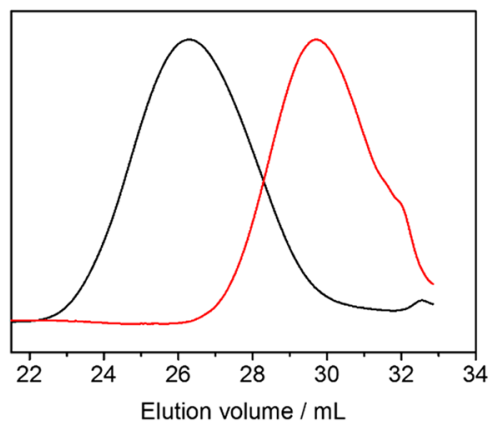

B

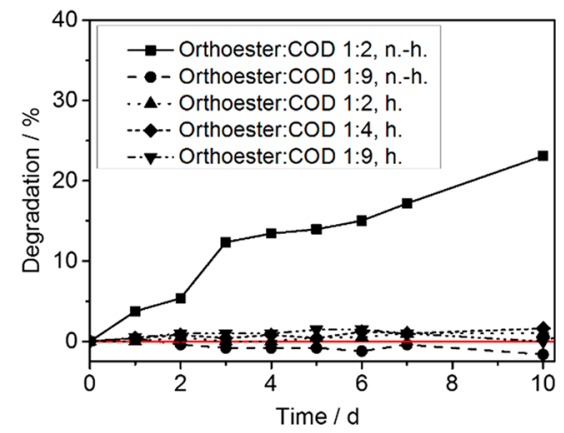

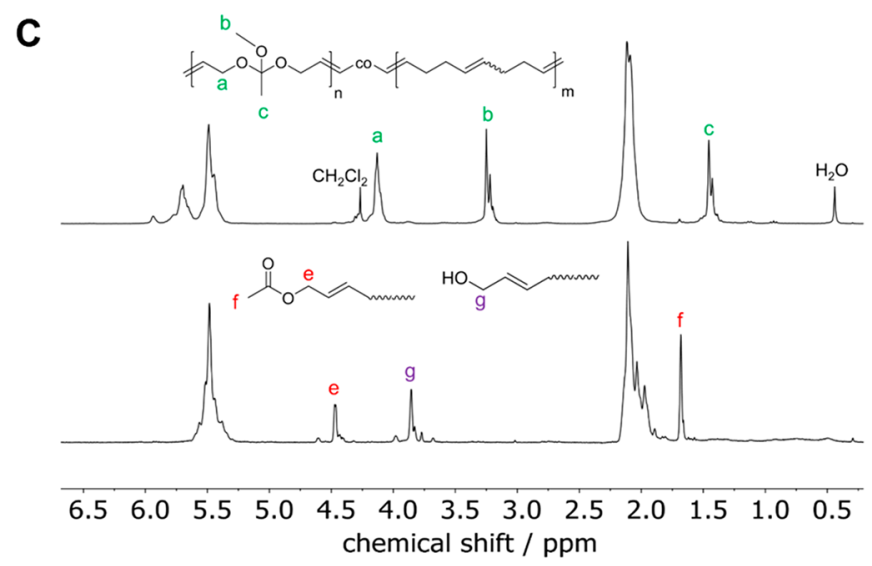

Figure 6. (A) SEC elugram (in THF) of poly(3)-co-COD before (black) and after degradation by hydrolysis (red). (B) Manometric respirometry biodegradation test of hydrogenated (h.) and non-hydrogenated (n.h.) poly(2)-co-COD using activated sludge from a local sewage plant. (C) ${ }^{1} \mathrm{H}$ NMR (300 MHz at $298 \mathrm{~K}$, in $\mathrm{C}_{6} \mathrm{D}_{6}$ ) of poly(1)-co-COD (top) and after hydrolysis (bottom) with peak assignments. 
von Delius and co-workers proved that relative to the electron density induced by the R-group hydrolysis the rate increases from $\mathrm{CH}_{2} \mathrm{Cl}<\mathrm{H}<\mathrm{Me}^{26}$ Thus, our PE mimics were expected to exhibit an adjustable hydrolysis rate. In general, the unsaturated polymers exhibited shelf lives of below 6 months of storage (at room temperature under air), indicating hydrolysis of the honey-like materials from atmospheric moisture; the $M_{n}$ of poly(3)-co-COD decreased from 8400 to $900 \mathrm{~g} \mathrm{~mol}^{-1}$ after storing the sample for 6 months without any precautions (Figure 6A). Comparing the ${ }^{1} \mathrm{H}$ NMR spectrum of poly(1)-co-COD directly after the synthesis with the spectrum after 6 months of storage, all corresponding orthoester signals had vanished completely (Figure 6C). Instead, peaks corresponding to the hydrolysis products (methyl ester and alcohol) were detected. We proceeded to examine the influence of the orthoester substituent on the hydrolytic degradation in a solution of the non-hydrogenated copolymers poly (1)-co-COD $(\mathrm{R}=-\mathrm{Me})$, poly (2)-co-COD ( $\mathrm{R}$ $=-\mathrm{H})$, and poly $(4)-c o-\mathrm{COD}\left(\mathrm{R}=-\mathrm{CH}_{2} \mathrm{Cl}\right)$. We performed these hydrolysis tests in $d$-THF and added 10 vol $\%$ of a solution of trifluoroacetic acid (TFA) in $\mathrm{D}_{2} \mathrm{O}$ (i.e., $0.4 \mathrm{~mol} \%$ TFA in relation to the orthoester). The reactions were monitored by ${ }^{1} \mathrm{H}$ NMR spectroscopy to determine the kinetic rate $k$ and the half-life $t_{1 / 2}$ of hydrolysis. Our results were in agreement with the earlier findings of von Delius et al. ${ }^{26}$ More electron-deficient orthoesters $\left(\mathrm{R}=-\mathrm{CH}_{2} \mathrm{Cl}, t_{1 / 2}=111 \mathrm{~h}\right)$ were found to be more stable than orthoformates $\left(\mathrm{R}=\mathrm{H}, t_{1 / 2}=10\right.$ $\mathrm{h})$, which in turn were found to be more stable than electronrich orthoacetates $\left(\mathrm{R}=\mathrm{Me}, t_{1 / 2}=3 \mathrm{~min}\right)$ (Table 3$)$.

Table 3. $k$ and $t_{1 / 2}$ Values for Hydrolysis in $d$-THF with TFA in $\mathrm{D}_{2} \mathrm{O}$ Observed by ${ }^{1} \mathrm{H} \mathrm{NMR}$ at $298 \mathrm{~K}$

\begin{tabular}{llcr}
\multicolumn{1}{c}{ polymer } & substituent & $k\left[\mathrm{~s}^{-1}\right]$ & $t_{1 / 2}[\mathrm{~min}]$ \\
\hline $\operatorname{poly}(1)_{1}-c o-\mathrm{COD}_{2}$ & $-\mathrm{Me}$ & $3.8 \times 10^{-3}$ & 3 \\
$\operatorname{poly}(2)_{1}-c o-\mathrm{COD}_{2}$ & $-\mathrm{H}$ & $1.9 \times 10^{-5}$ & 583 \\
$\operatorname{poly}(4)_{1}-c o-\mathrm{COD}_{2.5}$ & $-\mathrm{CH}_{2} \mathrm{Cl}$ & $1.7 \times 10^{-6}$ & 6651 \\
\hline
\end{tabular}

Polymer biodegradation studies in aerobic aqueous medium were performed according to the OECD $301 \mathrm{~F}$ guideline for ready biodegradability using activated sludge from the local sewage treatment plant in Mainz, Germany, as the inoculum. ${ }^{37}$ During this manometric respirometry test, the microorganism of the activated sludge converted the polymer to $\mathrm{CO}_{2}$ under aerobic conditions. The $\mathrm{CO}_{2}$ is trapped by $\mathrm{KOH}$ leading to a pressure decrease in the system. This pressure decrease can be measured and allows the calculation of the amount of biodegradation. For this test, we used an Oxitop setup and starch as the positive control. We tested three different copolymers: non-hydrogenated poly $(3)_{1}-\mathrm{co}-\mathrm{COD}_{2}$ and poly(3) $)_{1}$-co- $\mathrm{COD}_{9}$, the hydrogenated copolymers poly $(3)_{1}-\mathrm{co}$ $\mathrm{COD}_{2}$, poly $(3)_{1}-$ co- $\mathrm{COD}_{3}$ and poly $(3)_{1}-$ co- $\mathrm{COD}_{9}$ (Figure $6 \mathrm{~B})$. We followed literature procedures for biodegradation tests of hydrophobic compounds and doubled the amount of inoculum in comparison to the OECD guideline. ${ }^{38}$ The surface of the polymers was increased prior to the test by emulsification (by ultrasound) of the oily non-hydrogenated polymers and by grinding of the solid hydrogenated polymer. The test was performed at a constant temperature of $20{ }^{\circ} \mathrm{C}$. For the non-hydrogenated polymers, almost $25 \%$ of poly $(3)_{1}$ co- $\mathrm{COD}_{2}$ was degraded after 10 days while no significant degradation of poly $(3)_{1}$-co-COD 9 was observed. Because of the aqueous media, we assume that first hydrolysis of the copolymers occurs followed by the mineralization of the hydrolysis products (alcohols and esters) to $\mathrm{CO}_{2}$ and $\mathrm{H}_{2} \mathrm{O}$ by the microorganism. For fatty acid esters, the biodegradation rates decrease with increasing chain length. ${ }^{39,40}$ Because the hydrolysis products of poly(3)-co-COD are similar to them, this can explain the different biodegradability of poly $(3)_{1}-c o-$ $\mathrm{COD}_{2}$ in comparison to poly $(3)_{1}-c o-\mathrm{COD}_{9}$. None of the hydrogenated polymers showed any biodegradability after 20 days. This can be explained by the increased hydrophobicity of the saturated polymers in comparison to the unsaturated polymers. However, the OECD $301 \mathrm{~F}$ test aims to survey ready biodegradation ( $90 \%$ biodegradation within 30 days) and is optimized for water-soluble compounds. Thus, different longterm biodegradation tests for the long run have to be performed in the future to test the biodegradability of the synthesized orthoester copolymers. The fact that the ${ }^{1} \mathrm{H}$ NMR spectrum for the hydrogenated copolymers (e.g., poly $(3)_{1}$-co$\mathrm{COD}_{2}$, Figure S31) reveals hydrolysis after 6 months storage (at room temperature under air) suggests that further biodegradation is possible after this time.

\section{EXPERIMENTAL SECTION}

Materials. All commercially available reagents were purchased from Sigma-Aldrich, Alfa Aesar, Acros Organics, or TCI and were used without further purification unless otherwise stated. cis-2-Butene1,4-diol was stored over dried $3 \AA$ molecular sieves. Deuterated solvents were purchased from Sigma-Aldrich. All solvents were dried over molecular sieves for at least $24 \mathrm{~h}$; chloroform- $d$ was stored over anhydrous sodium carbonate, to quench residual acid, and activated 3 $\AA$ molecular sieves. Benzene- $d_{6}$ and toluene- $d_{8}$ were stored over activated 3 Å molecular sieves.

Instrumentation and Characterization Techniques. Size exclusion chromatography (SEC) measurements were performed in THF on an Agilent Technologies 1260 instrument consisting of an autosampler, a pump, and a column oven. The column set consists of three columns-SDV $10^{6} \AA$, SDV $10^{4} \AA$, and SDV $500 \AA$ (PSS Standards Service GmbH, Mainz, Germany), all of $300 \times 8 \mathrm{~mm}^{2}$ and $10 \mu \mathrm{m}$ average particle size-which were used at a flow rate of 1.0 $\mathrm{mL} / \mathrm{min}$ and a column temperature of $30{ }^{\circ} \mathrm{C}$. The injection volume was $100 \mu \mathrm{L}$. Detection was accomplished with an RI detector (Agilent Technologies). The data acquisition and evaluation were performed using PSS WINGPC UniChrom (PSS Polymer Standards Service $\mathrm{GmbH}$, Mainz, Germany). Calibration was performed by using polystyrene provided by PSS Polymer Standards Service $\mathrm{GmbH}$ (Mainz, Germany). For nuclear magnetic resonance (NMR) analysis ${ }^{1} \mathrm{H}$ and ${ }^{13} \mathrm{C}$ NMR spectra of the monomers were recorded on a Bruker AVANCE III 300, 400, 500, or $700 \mathrm{MHz}$ spectrometer. All spectra were measured in either $\mathrm{CDCl}_{3}, \mathrm{C}_{6} \mathrm{D}_{6}$, toluene- $d_{8}$, or THF- $d_{8}$ at $298 \mathrm{~K}$ or in toluene- $d_{8}$ at $353 \mathrm{~K}$. The spectra were calibrated against the solvent signal and analyzed using a MestReNova 12 from Mestrelab Research S.L. The thermal properties of the synthesized polymers have been measured by differential scanning calorimetry (DSC) on a Mettler Toledo DSC 823 calorimeter. Three scanning cycles of heating/cooling were performed in a nitrogen atmosphere $(30 \mathrm{~mL} / \mathrm{min})$ with a heating and cooling rate of $10^{\circ} \mathrm{C} / \mathrm{min}$. TGA was measured on a Mettler Toledo ThermoSTAR TGA/SDTA 851Thermowaage in a nitrogen atmosphere. The heating rate was $10{ }^{\circ} \mathrm{C} /$ min in a range of temperature between 35 and $600-900{ }^{\circ} \mathrm{C}$. Dynamic mechanical analysis (DMA) was performed using an Advanced Rheometric Expansion System (ARES) equipped with a forcerebalanced transducer. Plate/plate geometry was used with plate diameters of $6 \mathrm{~mm}$. The gap between plates was around $1 \mathrm{~mm}$. Experiments were performed under dry nitrogen atmosphere. The isochronal temperature dependencies of $G^{\prime}$ and $G^{\prime \prime}$ were determined for $\omega=10 \mathrm{rad} / \mathrm{s}$. For wide-angle X-ray scattering (WAXS) experiments were performed using a Philips PW1820 powder diffractometer with $\mathrm{Cu}$ radiation (wavelength $1.5418 \AA$ ). The crystal 
morphology, thickness, and crystal structure were determined using an FEI Tecnai F20 transmission electron microscope operated at an acceleration voltage of $200 \mathrm{kV}$. Bright-field (BF) and energy-filtered transmission electron microscopy (EFTEM) techniques were used for measurements. As solution-grown crystals lie flat-on on the supporting carbon film, their thickness was measured by EFTEM. The thickness estimation obtained from EFTEM was determined by

$$
\frac{I_{0}}{I_{t}}=\exp \left(-\frac{t}{\lambda}\right)
$$

where $I_{\mathrm{t}}$ is the total intensity of the inelastic spectrum energy, $I_{0}$ is the zeroth loss intensity of elastic spectrum energy, $\lambda$ is the mean free path, and $t$ is the thickness of the specimen. The relative thickness of the specimen $t / \lambda$ can be directly determined by thickness mapping from EFTEM. The value of the mean free path $\lambda$ depends on the composition of the specimen and on the convergence and collection semiangles of the TEM. Actually, the mean free paths of the carbon support, $\operatorname{poly}(3)_{1}-c o-\mathrm{COD}_{2}$, and poly $(3)_{1}-c o-\mathrm{COD}_{5}$ were determined to $\lambda_{\mathrm{C}}=241 \mathrm{~nm}, \lambda_{\text {poly }(3)-c o-\mathrm{COD}_{2}}=291 \mathrm{~nm}$, and $\lambda_{\text {poly }(3)_{1}-c o-\mathrm{COD}_{\mathrm{s}}}=294$ $\mathrm{nm}$, respectively. The information contained in a thickness map image is the relative thickness $t / \lambda$ and contains the superposition of the crystal lamellae and the supporting carbon film underneath. Accordingly, it is necessary to deconvolve these two in terms of thickness. It is easy to measure the thickness $t_{\mathrm{C}}$ of the carbon support alone. From the measured relative thickness $t / \lambda$ of support and crystal it is then straightforward to calculate the crystal thickness $t_{\text {crystal. }}$. For hydrolysis tests, 11-13 mg of each copolymer was dissolved in 550 $\mu \mathrm{L}$ of $d$-THF, and $50 \mu \mathrm{L}$ of a $8.7 \times 10^{-3}$ M TFA in $\mathrm{D}_{2} \mathrm{O}$ solution was added directly before the start of the measurements. The hydrolysis reaction was monitored by ${ }^{1} \mathrm{H}$ NMR spectroscopy using a Bruker AVANCE III 500 spectrometer over a period of $2 \mathrm{~h}$ to 5 days. Biodegradation tests were performed using a WTW OxiTop IS 6 device. All bottles were equipped with a stirring bar, a rubber tubular charged with two pellets of $\mathrm{KOH}$ (to bind $\mathrm{CO}_{2}$ ) and a measuring head. Activated sludge from the local sewage treatment plant in Mainz, Germany, was used as the inoculum. The activated sludge was aerated for 2 days prior to the biodegradation tests to minimize the residual organic content inside. All mineral media were prepared according to OECD guideline $301 .^{37}$ The inoculum was added without filtration to give an overall solid content of the inoculum of ca. $60 \mathrm{mg} \mathrm{mL}$. Between 27 and $34 \mathrm{mg}$ of the test substances were added to each bottle to achieve a theoretical oxygen demand of about $80 \mathrm{mg} \mathrm{L}^{-1}$. The oily, non-hydrogenated polymers were dispersed in the mineral medium and further ultrasonificated for $5 \mathrm{~min}$ prior to the addition to the bottles. Solid, hydrogenated polymers were grinded to minimize the particle size. Biodegradation tests were performed, in duplicate, over 30 days at a constant temperature of $20^{\circ} \mathrm{C}$. Starch was used as a positive control, and two bottles contained solely the inoculum and the mineral media to determine the blank value.

Synthetic Procedures. Synthesis of 2-Chloro-1,1,1-trimethoxyethane. 2-Chloro-1,1,1-trimethoxyethane was prepared according to the procedure reported by Moos et $\mathrm{al}^{41}$

General Experimental Procedure for the Synthesis of Cyclic Orthoester Monomers. ${ }^{42}$ An oven-dried round-bottom flask equipped with a stirring bar was charged with orthoester (1.2 equiv) and cis-2-butene-1,4-diol (1 equiv). One drop of concentrated sulfuric acid was added to the reaction mixture under vigorous stirring. The reaction mixture was stirred at room temperature until all starting material was consumed $\left({ }^{1} \mathrm{H}\right.$ NMR control) which took approximately $30-40 \mathrm{~min}$. Anhydrous sodium carbonate $(300 \mathrm{mg})$ was added to quench the acid. We noticed that too long reaction times can lead to the decomposition of the target compound. The reaction mixture was decanted and immediately distilled under reduced pressure $\left(10^{-2} \mathrm{bar}\right)$ with a short Vigreux column to yield the desired monomers as colorless liquids. If necessary to obtain high purities, distillation was repeated several times.

2-Methoxy-2-methyl-4,7-dihydro-1,3-dioxepine (1). Yield: $22 \%$. ${ }^{1} \mathrm{H}$ NMR (400 MHz, $\left.\mathrm{CDCl}_{3}\right): \delta 5.65(\mathrm{t}, J=1.7 \mathrm{~Hz}, 2 \mathrm{H}), 4.38-4.45$ (m, 2H), 4.16-4.10 (m, 2H), $3.34(\mathrm{~s}, 1 \mathrm{H}), 1.51(\mathrm{~s}, 3 \mathrm{H}) .{ }^{13} \mathrm{C}$ NMR $\left(101 \mathrm{MHz}, \mathrm{CDCl}_{3}\right): \delta 128.79,116.32,61.39,50.89,18.26$.

2-Methoxy-4,7-dihydro-1,3-dioxepine (2). Yield: 39\%. ${ }^{1} \mathrm{H}$ NMR $\left(400 \mathrm{MHz}, \mathrm{CDCl}_{3}\right): \delta 5.71(\mathrm{t}, J=1.7 \mathrm{~Hz}, 2 \mathrm{H}), 5.39(\mathrm{~s}, 1 \mathrm{H}), 4.51-$ $4.43(\mathrm{~m}, 2 \mathrm{H}), 4.17-4.09(\mathrm{~m}, 2 \mathrm{H}), 3.40(\mathrm{~s}, 3 \mathrm{H}) .{ }^{13} \mathrm{C}$ NMR $(101$ $\left.\mathrm{MHz}, \mathrm{CDCl}_{3}\right): \delta 129.15,113.71,61.51,53.52$.

2-Isopropoxy-4,7-dihydro-1,3-dioxepine (3). Yield: $66 \%{ }^{1} \mathrm{H}$ NMR $\left(400 \mathrm{MHz}, \mathrm{CDCl}_{3}\right): \delta 5.68(\mathrm{t}, J=1.8 \mathrm{~Hz}, 1 \mathrm{H}), 5.55(\mathrm{~s}$, $1 \mathrm{H}), 4.50-4.43(\mathrm{~m}, 2 \mathrm{H}), 4.13-4.07(\mathrm{~m}, 2 \mathrm{H}), 3.96$ (hept, $J=8.3,6.2$ $\mathrm{Hz}, 1 \mathrm{H}), 1.21(\mathrm{~d}, J=6.3 \mathrm{~Hz}, 6 \mathrm{H}) \cdot{ }^{13} \mathrm{C} \mathrm{NMR}\left(101 \mathrm{MHz}, \mathrm{CDCl}_{3}\right): \delta$ $129.20,111.67,68.45,61.39,22.57$.

2-(Chloromethyl)-2-methoxy-4,7-dihydro-1,3-dioxepine (4). Yield: $75 \% .{ }^{1} \mathrm{H}$ NMR $\left(400 \mathrm{MHz}, \mathrm{CDCl}_{3}\right): \delta 5.61(\mathrm{t}, J=1.8 \mathrm{~Hz}$, $2 \mathrm{H}), 4.46-4.39(\mathrm{~m}, 2 \mathrm{H}), 4.19-4.12(\mathrm{~m}, 2 \mathrm{H}), 3.66(\mathrm{~s}, 2 \mathrm{H}), 3.34(\mathrm{~s}$,

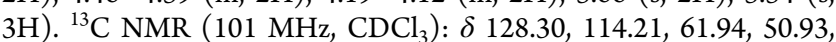
39.98 .

Representative Procedure for the Ring-Opening Metathesis Polymerization. The first-generation Grubbs-Hoveyda catalyst (5 $\mathrm{mg}$ ) was charged in a $2 \mathrm{~mL}$ screw-top vial equipped with a stirring bar and flushed with argon before the vial was closed with a lid containing a septum. The respective orthoester monomer 2 (144 mg, $1.1 \mathrm{mmol})$ and 1,5-cyclooctadiene (239 $\mathrm{mg}, 2.2 \mathrm{mmol}$ ) were degassed by bubbling argon through the solution prior to the addition to the initiator via a syringe. The initiator quickly dissolved in the monomer mixture. The polymerization was conducted at room temperature and vigorous stirring. An increase in viscosity indicated the ongoing polymerization process. After $17 \mathrm{~h}, 1 \mathrm{~mL}$ of dichloromethane was added to dissolve the polymer, then $100 \mu \mathrm{L}$ of ethyl vinyl ether to quench the polymerization, and $100 \mu \mathrm{L}$ of trimethylamine to prevent hydrolysis. The mixture was further diluted with dichloromethane before precipitating from methanol containing a few droplets of trimethylamine. After centrifugation, the product was isolated and dried under reduced pressure to yield a brown, honey-like polymer. The ROMP polymers were obtained in $40-83 \%$ yield.

Poly(1)-co-COD. ${ }^{1} \mathrm{H}$ NMR (300 MHz, benzene- $\left.d_{6}\right): \delta 5.72(\mathrm{~m}$, $\left.-\mathrm{O}-\mathrm{CH}_{2}-\mathrm{CH}=\right), 5.48\left(\mathrm{~m},-\mathrm{CH}_{2}-\mathrm{CH}=(\mathrm{COD})\right), 4.13(\mathrm{~m},-\mathrm{O}-$ $\left.\mathrm{C}_{2}-\mathrm{CH}=\right), 3.23\left(\mathrm{~s},-\mathrm{O}-\mathrm{CH}_{3}\right), 2.09\left(\mathrm{~m},-\mathrm{CH}_{2}-\mathrm{CH}=(\mathrm{COD})\right)$, $1.44\left(\mathrm{~s},-\mathrm{C}-\mathrm{CH}_{3}\right) .{ }^{13} \mathrm{C}$ NMR $\left(75 \mathrm{MHz}\right.$, benzene- $\left.d_{6}\right): \delta 132.11$, $129.73,63.21,49.71,34.69-31.16(\mathrm{~m}), 27.49,20.19$.

Poly(2)-co-COD. ${ }^{1} \mathrm{H}$ NMR (300 MHz, benzene- $\left.d_{6}\right): \delta 5.65(\mathrm{~m}$, $\left.-\mathrm{O}-\mathrm{CH}_{2}-\mathrm{CH}=\right)$, 5.57-5.35 (m, $\left.-\mathrm{CH}_{2}-\mathrm{CH}=(\mathrm{COD})\right), 5.27-5.17$ $(\mathrm{s},-\mathrm{CH}), 4.20-4.00\left(\mathrm{~m},-\mathrm{O}-\mathrm{CH}_{2}-\mathrm{CH}=\right), 3.23\left(\mathrm{~s},-\mathrm{O}-\mathrm{CH}_{3}\right), 2.09$ $\left(\mathrm{m},-\mathrm{CH}_{2}-\mathrm{CH}=(\mathrm{COD})\right) \cdot{ }^{13} \mathrm{C}$ NMR $\left(75 \mathrm{MHz}\right.$, benzene- $\left.d_{6}\right): \delta$ 133.09, 130.04, 64.89, 50.74, 33.77-31.37 (m), 27.45.

Poly(3)-co-COD. ${ }^{1} \mathrm{H}$ NMR (300 MHz, benzene- $\left.d_{6}\right): \delta 5.76-5.59$ $\left(\mathrm{m},-\mathrm{O}-\mathrm{CH}_{2}-\mathrm{CH}=\right), 5.58-5.40\left(\mathrm{~m},-\mathrm{CH}_{2}-\mathrm{CH}=(\mathrm{COD})\right), 5.40-$ $5.30(\mathrm{~s},-\mathrm{C} \underline{\mathrm{H}}), 4.17\left(\mathrm{~m},-\mathrm{O}-\mathrm{C}_{2}-\mathrm{CH}=\right), 4.00(\mathrm{~m},-\mathrm{O}-\mathrm{C} \underline{\mathrm{H}}-$ $\left.\left(\mathrm{CH}_{3}\right)_{2}\right), 2.10\left(\mathrm{~m},-\mathrm{CH}_{2}-\mathrm{CH}=(\mathrm{COD})\right), 1.16(\mathrm{~m},-\mathrm{O}-\mathrm{CH}-$ $\left.\left(\mathrm{CH}_{3}\right)_{2}\right) \cdot{ }^{13} \mathrm{C}$ NMR $\left(75 \mathrm{MHz}\right.$, benzene- $\left.d_{6}\right): \delta 130.36,127.26,67.18$, 58.36, 38.40, 25.30, 23.76.

Poly(4)-Co-COD. ${ }^{1} \mathrm{H}$ NMR (300 MHz, benzene- $\left.d_{6}\right): \delta 5.65(\mathrm{~m}$, $\left.-\mathrm{O}-\mathrm{CH}_{2}-\mathrm{C} \underline{\mathrm{H}}=\right)$, 5.58-5.34 (m, $\left.-\mathrm{CH}_{2}-\mathrm{C} \underline{\mathrm{H}}=(\mathrm{COD})\right), 4.20-3.96$ $\left(\mathrm{m},-\mathrm{O}-\mathrm{CH}_{2}-\mathrm{CH}=\right), 3.50\left(\mathrm{~s},-\mathrm{CH}_{2}-\mathrm{Cl}\right), 3.18\left(\mathrm{~s},-\mathrm{O}-\mathrm{CH}_{3}\right), 2.09$ $\left(\mathrm{m},-\mathrm{CH}_{2}-\mathrm{CH}=(\mathrm{COD})\right) .{ }^{13} \mathrm{C}$ NMR $\left(75 \mathrm{MHz}\right.$, benzene- $\left.d_{6}\right): \delta$ 133.11, 130.45, 63.89, 50.24, 43.51, 33.25, 27.32.

Representative Procedure for Hydrogenation. The polymer (300 $\mathrm{mg}$ ) was dissolved in $10 \mathrm{~mL}$ of dry toluene in a glass vessel, and the solution was degassed by bubbling argon through the solution for 15 min. $50 \mathrm{mg}$ of 10 wt $\% \mathrm{Pd} / \mathrm{CaCO}_{3}$ was added, and the glass vessel was charged into a $250 \mathrm{~mL}$ ROTH autoclave. Hydrogenation was performed at $70{ }^{\circ} \mathrm{C}$ and 70 bar of $\mathrm{H}_{2}$. After completion of the reaction, hot toluene was added, and the hot reaction mixture was filtered and directly precipitated from cold methanol (containing $\mathrm{NEt}_{3}$ to prevent hydrolysis). After centrifugation, the product was isolated and dried at reduced pressure to yield the polymer as an off-white powder. Yields were between $60 \%$ to quantitative yield.

Poly(1)-Co-COD, Hydrogenated. ${ }^{1} \mathrm{H}$ NMR $(500 \mathrm{MHz}$, toluene$\left.d_{8}\right): \delta 3.55\left(\mathrm{~m},-\mathrm{O}-\mathrm{CH}_{2}-\mathrm{CH}_{2}-\right), 3.20\left(\mathrm{~s},-\mathrm{O}-\mathrm{CH}_{3}\right), 1.61(\mathrm{~m}$, $-\mathrm{O}-\mathrm{CH}_{2}-\mathrm{CH}_{2}-$ ), 1.33 (b, alkyl backbone). 
Poly(2)-Co-COD, Hydrogenated. ${ }^{1} \mathrm{H}$ NMR (700 MHz, toluene$\left.d_{8}\right): \delta 5.05(\mathrm{~s},-\mathrm{C} \underline{\mathrm{H}}), 3.36\left(\mathrm{~m},-\mathrm{O}-\mathrm{CH}_{2}-\mathrm{CH}_{2}-\right), 3.21(\mathrm{~s},-\mathrm{O}-$ $\mathrm{CH}_{3}$ ), 1.59 (m, $-\mathrm{O}-\mathrm{CH}_{2}-\mathrm{CH}_{2}-$ ), 1.52-1.09 (b, alkyl backbone). Poly(3)-co-COD, Hydrogenated. ${ }^{1} \mathrm{H}$ NMR (500 MHz, toluene$\left.d_{8}\right): \delta 5.21(\mathrm{~s},-\mathrm{C} \underline{\mathrm{H}}), 3.97\left(\mathrm{~m},-\mathrm{O}-\mathrm{C} \underline{\mathrm{H}}-\left(\mathrm{CH}_{3}\right)_{2}\right), 3.75-3.46(\mathrm{~m}$, $\left.-\mathrm{O}-\mathrm{CH}_{2}-\mathrm{CH}_{2}-\right), 1.76-1.52\left(\mathrm{~m},-\mathrm{O}-\mathrm{CH}_{2}-\mathrm{CH}_{2}-\right), 1.34$ (b, alkyl backbone), 1.18 (d, $\left.-\mathrm{O}-\mathrm{CH}-\left(\mathrm{C}_{3}\right)_{2}\right)$.

Poly(4)-co-COD, Hydrogenated. ${ }^{1} \mathrm{H}$ NMR (500 MHz, toluene$\left.d_{8}\right): \delta 3.73-3.55\left(\mathrm{~m},-\mathrm{O}-\mathrm{C}_{2}-\mathrm{CH}_{2}-\right), 3.53\left(\mathrm{~s},-\mathrm{C}_{2}-\mathrm{Cl}\right), 3.24$ $\left(\mathrm{s},-\mathrm{O}-\mathrm{CH}_{3}\right), 1.68-1.52\left(\mathrm{~m},-\mathrm{O}-\mathrm{CH}_{2}-\mathrm{CH}_{2}-\right), 1.36$ (b, alkyl backbone).

\section{SUMMARY}

In this work, we report the synthesis of polyorthoesters by ring-opening metathesis polymerization (ROMP). Four different orthoester monomers were copolymerized with 1,5cyclooctadiene (COD) in different ratios to yield unsaturated polymers with molecular weights up to $38000 \mathrm{~g} \mathrm{~mol}^{-1}$. Postpolymerization hydrogenation gave hard, solid materials with thermal properties similar to polyethylene. The number of orthoester units in the polymer chain influenced thermal properties such as melting point or onset temperature of decomposition. Because of the brittle nature of the material, future work will focus on increasing the molecular weight of the long-chain polyorthoesters to better mimic the mechanical properties of polyethylene. Nevertheless, the biodegradability of the unsaturated orthoester copolymers represents a potential advantage when compared to polyethylene. All copolymers, hydrogenated and non-hydrogenated, hydrolyze slowly when exposed to atmospheric moisture. The hydrolysis rate in solution was found to be dependent on the orthoester substituent. In conclusion, long-chain polyorthoester copolymers are promising materials with the potential of replacing polyethylene for applications where a degradation over time is advantageous.

\section{ASSOCIATED CONTENT}

\section{S Supporting Information}

The Supporting Information is available free of charge on the ACS Publications website at DOI: 10.1021/acs.macromol.9b00180.

Analytical and spectral characterization data as well as evaluation of biodegradation test (PDF)

\section{AUTHOR INFORMATION}

\section{Corresponding Author}

*E-mail wurm@mpip-mainz.mpg.de, Ph 00496131 379581, Fax 00496131370330 (F.R.W.).

\section{ORCID}

Ingo Lieberwirth: 0000-0003-1323-524X

Max von Delius: 0000-0003-1852-2969

Frederik R. Wurm: 0000-0002-6955-8489

\section{Notes}

The authors declare no competing financial interest.

\section{ACKNOWLEDGMENTS}

The authors thank the German Federal Ministry for Education and Research (BMBF) for their support of the program "Research for sustainable development (FONA)", "PlastX Plastics as a systemic risk for social-ecological supply systems" (grant 01UU1603A). O.Sh. and M.v.D. thank the University of Ulm and the German Research Foundation (DFG, Emmy-
Noether grant DE 1830/2-1) for financial support. O.Sh. is grateful for a doctoral scholarship by the German Academic Exchange Service (DAAD). We thank Michael Steiert (MPIP) for XRD measurements.

\section{REFERENCES}

(1) Bioplastics market data 2017; https://www.european-bioplastics. org/market/ (accessed 21.06.2018).

(2) Malpass, D. B. Introduction to Industrial Polyethylene: Properties, Catalysts, and Processes; Wiley: 2010.

(3) Haider, T. P.; Völker, C.; Kramm, J.; Landfester, K.; Wurm, F. R. Plastics of the Future? The Impact of Biodegradable Polymers on the Environment and on Society. Angew. Chem., Int. Ed. 2019, 58 (1), $50-62$.

(4) Stempfle, F.; Ortmann, P.; Mecking, S. Long-Chain Aliphatic Polymers To Bridge the Gap between Semicrystalline Polyolefins and Traditional Polycondensates. Chem. Rev. 2016, 116 (7), 4597-4641.

(5) Trzaskowski, J.; Quinzler, D.; Bährle, C.; Mecking, S. Aliphatic Long-Chain C20 Polyesters from Olefin Metathesis. Macromol. Rapid Commun. 2011, 32 (17), 1352-1356.

(6) Ortmann, P.; Lemke, T. A.; Mecking, S. Long-Spaced Polyamides: Elucidating the Gap between Polyethylene Crystallinity and Hydrogen Bonding. Macromolecules 2015, 48 (5), 1463-1472.

(7) Ortmann, P.; Wimmer, F. P.; Mecking, S. Long-Spaced Polyketones from ADMET Copolymerizations as Ideal Models for Ethylene/CO Copolymers. ACS Macro Lett. 2015, 4 (7), 704-707.

(8) Steinbach, T.; Alexandrino, E. M.; Wahlen, C.; Landfester, K.; Wurm, F. R. Poly(phosphonate)s via Olefin Metathesis: Adjusting Hydrophobicity and Morphology. Macromolecules 2014, 47 (15), 4884-4893.

(9) Zheng, Y.-R.; Tee, H. T.; Wei, Y.; Wu, X.-L.; Mezger, M.; Yan, S.; Landfester, K.; Wagener, K.; Wurm, F. R.; Lieberwirth, I. Morphology and Thermal Properties of Precision Polymers: The Crystallization of Butyl Branched Polyethylene and Polyphosphoesters. Macromolecules 2016, 49 (4), 1321-1330.

(10) Ortmann, P.; Heckler, I.; Mecking, S. Physical properties and hydrolytic degradability of polyethylene-like polyacetals and polycarbonates. Green Chem. 2014, 16 (4), 1816-1827.

(11) Cordes, E. H. Mechanism and Catalysis for the Hydrolysis of Acetals, Ketals, and Ortho Esters. Prog. Phys. Org. Chem. 2007, 4, 144.

(12) Binauld, S.; Stenzel, M. H. Acid-degradable polymers for drug delivery: a decade of innovation. Chem. Commun. 2013, 49 (21), 2082-2102.

(13) Heller, J. Synthesis of Biodegradable Polymers for Biomedical Utilization. ACS Symp. Ser. 1983, 212, 373-392.

(14) Heller, J. In Poly(ortho esters); Springer: Berlin, 1993; pp 4192.

(15) Heller, J.; Barr, J. Poly(ortho esters)From Concept to Reality. Biomacromolecules 2004, 5 (5), 1625-1632.

(16) Ng, S. Y.; Shen, H. R.; Lopez, E.; Zherebin, Y.; Barr, J.; Schacht, E.; Heller, J. Development of a poly(ortho ester) prototype with a latent acid in the polymer backbone for 5-fluorouracil delivery. $J$. Controlled Release 2000, 65 (3), 367-374.

(17) Wolfe, P. S.; Wagener, K. B. An ADMET route to unsaturated polyacetals. Macromol. Rapid Commun. 1998, 19 (6), 305-308.

(18) Khaja, S. D.; Lee, S.; Murthy, N. Acid-Degradable Protein Delivery Vehicles Based on Metathesis Chemistry. Biomacromolecules 2007, 8 (5), 1391-1395.

(19) Fraser, C.; Hillmyer, M. A.; Gutierrez, E.; Grubbs, R. H. Degradable Cyclooctadiene/Acetal Copolymers: Versatile Precursors to 1,4-Hydroxytelechelic Polybutadiene and Hydroxytelechelic Polyethylene. Macromolecules 1995, 28 (21), 7256-7261.

(20) Chikkali, S.; Stempfle, F.; Mecking, S. Long-Chain Polyacetals From Plant Oils. Macromol. Rapid Commun. 2012, 33 (13), 11261129. 
(21) Heller, J.; Barr, J.; Ng, S. Y.; Abdellauoi, K. S.; Gurny, R. Poly(ortho esters): synthesis, characterization, properties and uses. Adv. Drug Delivery Rev. 2002, 54 (7), 1015-1039.

(22) Tschan, M. J.-L.; Ieong, N. S.; Todd, R.; Everson, J.; Dove, A. P. Unlocking the Potential of Poly(Ortho Ester)s: A General Catalytic Approach to the Synthesis of Surface-Erodible Materials. Angew. Chem., Int. Ed. 2017, 56 (52), 16664-16668.

(23) Shyshov, O.; Brachvogel, R.-C.; Bachmann, T.; Srikantharajah, R.; Segets, D.; Hampel, F.; Puchta, R.; von Delius, M. Adaptive Behavior of Dynamic Orthoester Cryptands. Angew. Chem., Int. Ed. 2017, 56 (3), 776-781.

(24) Brachvogel, R.-C.; Hampel, F.; von Delius, M. Self-assembly of dynamic orthoester cryptates. Nat. Commun. 2015, 6, 7129.

(25) Brachvogel, R.-C.; von Delius, M. Orthoester exchange: a tripodal tool for dynamic covalent and systems chemistry. Chem. Sci. 2015, 6 (2), 1399-1403.

(26) Low, H.; Mena-Osteritz, E.; von Delius, M. Self-assembled orthoester cryptands: orthoester scope, post-functionalization, kinetic locking and tunable degradation kinetics. Chem. Sci. 2018, 9, 4785.

(27) Hilf, S.; Berger-Nicoletti, E.; Grubbs, R. H.; Kilbinger, A. F. M. Monofunctional Metathesis Polymers via Sacrificial Diblock Copolymers. Angew. Chem., Int. Ed. 2006, 45 (47), 8045-8048.

(28) Steinbach, T.; Alexandrino, E. M.; Wurm, F. R. Unsaturated poly(phosphoester)s via ring-opening metathesis polymerization. Polym. Chem. 2013, 4 (13), 3800-3806.

(29) Sutthasupa, S.; Shiotsuki, M.; Sanda, F. Recent advances in ring-opening metathesis polymerization, and application to synthesis of functional materials. Polym. J. 2010, 42, 905.

(30) Hejl, A.; Scherman, O. A.; Grubbs, R. H. Ring-Opening Metathesis Polymerization of Functionalized Low-Strain Monomers with Ruthenium-Based Catalysts. Macromolecules 2005, 38 (17), 7214-7218.

(31) Jung, M. E.; Piizzi, G. gem-Disubstituent Effect: Theoretical Basis and Synthetic Applications. Chem. Rev. 2005, 105 (5), 17351766.

(32) Neary, W. J.; Kennemur, J. G. A Precision Ethylene-Styrene Copolymer with High Styrene Content from Ring-Opening Metathesis Polymerization of 4-Phenylcyclopentene. Macromol. Rapid Commun. 2016, 37 (12), 975-979.

(33) Wagener, K. B.; Boncella, J. M.; Nel, J. G. Acyclic diene metathesis (ADMET) polymerization. Macromolecules 1991, 24 (10), 2649-2657.

(34) Nelson, D. J.; Manzini, S.; Urbina-Blanco, C. A.; Nolan, S. P. Key processes in ruthenium-catalysed olefin metathesis. Chem. Commun. 2014, 50 (72), 10355-10375.

(35) Liu, C.; Liu, F.; Cai, J.; Xie, W.; Long, T. E.; Turner, S. R.; Lyons, A.; Gross, R. A. Polymers from Fatty Acids: Poly $(\omega$-hydroxyl tetradecanoic acid) Synthesis and Physico-Mechanical Studies. Biomacromolecules 2011, 12 (9), 3291-3298.

(36) Busch, H.; Schiebel, E.; Sickinger, A.; Mecking, S. UltralongChain-Spaced Crystalline Poly(H-phosphonate)s and Poly(phenylphosphonate)s. Macromolecules 2017, 50 (20), 7901-7910.

(37) OECD Test No. 301: Ready Biodegradability, 1992.

(38) de Morsier, A.; Blok, J.; Gerike, P.; Reynolds, L.; Wellens, H.; Bontinck, W. J. Biodegradation tests for poorly-soluble compounds. Chemosphere 1987, 16 (4), 833-847.

(39) Kleeberg, I.; Welzel, K.; VandenHeuvel, J.; Müller, R. J.; Deckwer, W. D. Characterization of a New Extracellular Hydrolase from Thermobifida fusca Degrading Aliphatic-Aromatic Copolyesters. Biomacromolecules 2005, 6 (1), 262-270.

(40) Gerike, P. The biodegradability testing of poorly water soluble compounds. Chemosphere 1984, 13 (1), 169-190.

(41) Moos, W. H.; Gless, R. D.; Rapoport, H. Codeine analogs. Synthesis of spiro[benzofuran-3(2H)4'-piperidines] and octahydro1 H-benzofuro[3,2-e] isoquinolines. J. Org. Chem. 1981, 46 (25), 5064-5074.

(42) Pawlowski, C. Substituted 1,3-dioxepins. US3966768A, June 29, 1976. 